\title{
Identification of $\alpha(1,6)$ fucosylated proteins differentially expressed in human colorectal cancer
}

\author{
Laura Muinelo-Romay ${ }^{1}$, Susana Villar-Portela ${ }^{1}$, Elisa Cuevas ${ }^{2}$, Emilio Gil-Martín ${ }^{1 \dagger}$ and Almudena Fernández-Briera ${ }^{1{ }^{*+}}$
}

\begin{abstract}
Summary
Background: A universal hallmark of cancer cells is the change in their glycosylation phenotype. One of the most frequent alterations in the normal glycosylation pattern observed during carcinogenesis is the enhancement of $\alpha$ $(1,6)$ linked fucose residues of glycoproteins, due to the up-regulation of the $\alpha(1,6)$ fucosyltransferase activity. Our previous results demonstrated the specific alteration of this enzyme activity and expression in colorectal cancer, suggesting its implication in tumour development and progression.
\end{abstract}

Methods: In the current work we combined a LCA-affinity chromatography with SDS-PAGE and mass spectrometry in order to identify $\alpha(1,6)$ fucosylated proteins differentially expressed in colorectal cancer. This strategy allowed the identification of a group of $\alpha(1,6)$ fucosylated proteins candidates to be involved in CRC malignancy.

Results: The majority of the identified proteins take part in cell signaling and interaction processes as well as in modulation of the immunological response. Likewise, we confirmed the increased expression of GRP94 in colorectal cancer tissue and the significant down-regulation of the lgGFcBP expression in tumour cells.

Conclusion: All these results validate the importance of core-fucosylated proteins profile analysis to understand the mechanisms which promote cancer onset and progression and to discover new tumour markers or therapeutic targets.

Keywords: Colorectal cancer, Glycoproteins, $\alpha$ ?a?(1,6)fucosyltransferase, GRP94, IgGFcBP

\section{Background}

Colorectal carcinoma (CRC) is one of the most frequent tumours in the Western world. Although early stages are successfully treatable, many cases are undiagnosed until late stages when the prognosis is poor [1]. Therefore, the identification and verification of proteins that have a functional role in the patho-physiology of CRC remains an important goal to discover new biomarkers for diagnosis, prognosis and follow-up, as well as to find therapeutic targets.

Glycosylation plays fundamental roles in controlling various biological processes such as embryonic development, immune response and cell-cell interactions

\footnotetext{
* Correspondence: abriera@uvigo.es

† Contributed equally

'Department of Biochemistry, Genetics and Immunology, Faculty of Biology, University of Vigo, Campus As Lagoas-Marcosende S/N, 36310, Vigo, Spain
} Full list of author information is available at the end of the article involving sugar-sugar or sugar-protein specific recognition [2]. An universal hallmark of cancer cells is the change in their glycosylation phenotype, with several effects on this tumour cells behavior [3]. In this sense, glycosylation analysis has become an important target for proteomic research and has reached great interest to understand the molecular events associated with tumour development and progression.

One of the most frequent alterations in the normal glycosylation pattern observed during carcinogenesis is the enhancement of $\alpha(1,6)$ linked fucose residues of glycoproteins $[4,5]$. The enzyme responsible of this fucosylation step is the $\alpha(1,6)$ fucosyltransferase [FUT8, $\alpha(1,6)$ FT], which catalyzes the transfer of a fucose residue from GDP-fucose to the innermost GlcNAc of hybrid and complex $\mathrm{N}$-linked oligosaccharides via $\alpha(1,6)$ linkage. Numerous studies have demonstrated the key role of $\alpha$ $(1,6)$ fucosylation in the activity of proteins strongly
C Biomed Central 
implicated in both tumour growth, such as EGFR, TGFR- $\beta_{1}$ or VEGFR-2 [6-8], and tumour dissemination, for example, E-cadherin or $\alpha 3 \beta 1$ and $\alpha 5 \beta 1$ integrins [9-11]. In addition, several $\alpha(1,6)$ fucosylated proteins have been proposed as potential biomarkers for different types of tumours. The most representative case is the $\alpha$ $(1,6)$ fucosylated fraction of $\alpha$-fetoprotein (AFP-L3), currently employed as a specific tumour marker for hepatocarcinoma (HCC) [12]. Other aberrantly corefucosylated proteins such as GP73, haptoglobin (Hp), transferrin, $\alpha-1$-acid glycoprotein or $\alpha$-1-antitrypsin, have also been reported as promising serum biomarkers for HCC [13,14]. Moreover, an important elevation of serum fucosylated forms of $\mathrm{Hp}$ and RNase1 has been described in pancreatic tumours $[15,16]$.

The identification and validation of specific tissue and/ or serum $\alpha(1,6)$ fucosylated proteins which share altered expression levels is of great value to clarify the insights of the critical events in cancer progression. However, the proteomic analysis of glycoproteins is tedious because it requires their isolation from complex biological samples that contain both non glycosylated and very heterogeneously glycosylated proteins [17]. Thus, the application of different analytic approaches has revealed as the most efficient tool to study the tissue or serum profile of these proteins. In this sense, previous studies have achieved the affinity purification of $\alpha(1,6)$ fucosylated proteins using lectins that specifically recognize the $(1,6)$ fucose linkage, such as LCA (Lens culinaris agglutinin) [18] or AAL (Aleuria aurantia lectin) [19], followed by separation methods (HPLC or SDS-PAGE) and analytical LC-MS/ MS to identify the proteins differentially expressed and/ or fucosylated in cancer tissue [20,21].

We have previously reported the specific alteration of $\alpha(1,6)$ FT activity and expression in CRC, suggesting its implication in tumour development and progression $[22,23]$. To complete the knowledge about the importance of the $\alpha(1,6)$ fucosylation in CRC, in the present study we have undertaken an affinity enrichment approach to compare the $\alpha(1,6)$ fucosylated proteins profile of healthy and tumour colorectal tissues. This strategy has allowed us the identification of several $\alpha(1,6)$ fucosylated proteins as candidates to be involved in CRC malignancy. In particular, we observed a significant alteration of GRP94 and IgGFcBP expression levels in colorectal cancer tissue. These results validate the importance of core-fucosylated proteins profile analysis in CRC as a way to discover new tumour markers or therapeutic targets.

\section{Methods}

\section{Human tissue samples}

Paired colorectal tissue samples, both from tumour and adjacent healthy mucosa, were obtained from patients with CRC who underwent surgery at the University Complex Hospital of Ourense, Spain. Mucosa was considered healthy if distant by at least $10 \mathrm{~cm}$ from the tumour. The approval of the appropriate local Institutional Review Board as well as the informed consent from the patients, were obtained.

The specimens used for immunohistochemical analysis were fixed in formalin (10\%), embedded in paraffin $\left(60^{\circ}\right.$ C) and subjected to hematoxylin and eosin staining (standard procedure) for evaluating their microscopic features. The specimens employed for the chromatography enrichment and Western/Lectin blot analysis were washed with ice-cold saline buffer and stored frozen at $-85^{\circ} \mathrm{C}$ until use.

\section{Protein extraction}

Colorectal tissue was homogenized in 6 vol. of $0.01 \mathrm{M}$ Tris- $\mathrm{HCl}$ buffer (pH 7.4), containing $0.25 \mathrm{M}$ sucrose, $1 \%$ Triton X-100 and a cocktail of protease inhibitors (Complete $^{\mathrm{TM}}$ Mini tablets, Roche). The homogenate was centrifuged for $10 \mathrm{~min}$ at $15000 \mathrm{xg}$ and $4^{\circ} \mathrm{C}$. The supernatant obtained was recovered and the protein concentration of this final preparation (total fraction, TF) was determined by BCA protein assay, using bovine serum albumin as standard. The tissue extract was stored at $-20^{\circ} \mathrm{C}$ until use.

\section{$\alpha(1,6)$ fucosylated proteins enrichment with LCA-affinity chromatography}

LCA-affinity chromatography was performed as previously described by Dai et al. [21] with some modifications. LCA column was prepared by adding $4 \mathrm{~mL}$ of agarose-bound lectin (Sigma-Aldrich Aldrich) into polypropylene columns (Econo Column, Bio-Rad). The columns were equilibrated $a b$ initio with Tris- $\mathrm{HCl} 0.05$ $\mathrm{M}$ (pH 7.2). Once equilibrated, $1 \mathrm{~mL}$ of the total protein (TF) preparation was loaded onto the LCA column. After incubating for $10 \mathrm{~min}$, the unbounded proteins (FI) were washed out with $15 \mathrm{~mL}$ of equilibrating buffer. The unspecific retained proteins (FII) were then removed with $10 \mathrm{~mL}$ of Tris- $\mathrm{HCl} 0.05 \mathrm{M}$ (pH 7.2) containing $\mathrm{NaCl} 0.3 \mathrm{M}$. Finally, the specific bounded fraction (FIII) was eluted using $10 \mathrm{~mL}$ of Tris- $\mathrm{HCl} 0.05 \mathrm{M}$ (pH 7.2) containing $\mathrm{NaCl} 0.3 \mathrm{M}, \alpha-$ methyl-D-mannopyranoside $0.4 \mathrm{M}$ and $\alpha$-methyl-Dglycopyranoside $0.4 \mathrm{M}$. The chromatographic process was controlled by spectrophotometry at $280 \mathrm{~nm}$ with a UVIKON 930 spectrophotometer (Kontron Instruments). All fractions obtained were then centrifugated in Amicon Ultra-4 Centrifugal Filters Devices (Millipore) for concentrating and desalting. The protein recovery of the lectin column was determined by means of the BCA protein assay, using bovine serum albumin as standard. 
One-dimensional electrophoresis and lectin blot

20 and $10 \mu \mathrm{g}$ of protein from total extraction (TF) and FI, FII and FIII chromatography fractions were subjected in parallel to SDS-PAGE (12\% polyacrylamide gel) under reducing conditions. The gel loaded with $20 \mu \mathrm{g}$ of protein was stained with Coomassie Brilliant Blue R-250 (Bio-Rad). The proteins of the gel loaded with $10 \mathrm{~g}$ of protein were electrotransferred onto a polyvinylidene difluoride membrane (Hybond-P, Amersham Bioscience). After blotting, the membrane was washed with TBS containing $0.05 \%$ Tween-20 (T-TBS) (v/v), blocked with $3 \%(\mathrm{w} / \mathrm{v})$ dried serum albumin in T-TBS overnight at $4^{\circ} \mathrm{C}$, and incubated with $1 / 2,000$ biotinylated-LCA (Vector Laboratories) for $1 \mathrm{~h}$ at room temperature. After washing with T-TBS, the blot was incubated with $1 / 2,000$ diluted Streptavidin-Alkalin phosphatase (Sigma-Aldrich) for $1 \mathrm{~h}$ at room temperature. Finally, the blot was washed with T-TBS and the colour was developed using BCIP/NBT Liquid Substrate System (Sigma-Aldrich).

The band pattern and the intensity were obtained by densitometric analysis (GS-800 Calibrated Densitometer, Bio-Rad) using the Quantity One software for PC (BioRad). The relative intensity of FIII bands was employed for comparative analysis between healthy and tumour mucosa.

\section{Protein identification by mass spectrometry}

Differentially expressed bands present in FIII were excised from gels and sent for analysis to the Proteomics and Mass Spectrometry Facility at Parc Científic de Barcelona (Barcelona, Spain).

Proteins were in-gel digested with trypsin (Sequencing grade modified, Promega) in the automatic Investigator ProGest robot of Genomic Solutions. Briefly, excised gels spots were washed sequentially with ammonium bicarbonate buffer and acetonitrile. Proteins were reduced and alkylated by treatment with $10 \mathrm{mM}$ DTT solution during $30 \mathrm{~min}$, and treatment with a $55 \mathrm{mM}$ solution of iodine acetamide, respectively. After sequential washings with buffer and acetronitrile, proteins were digested overnight at $37^{\circ} \mathrm{C}$ with $0.27 \mathrm{nmol}$ trypsin. Tryptic peptides were extracted from the gel matrix with $10 \%$ formic acid and acetonitrile; the extracts were pooled and dried in a vacuum centrifuge.

Tryptic peptides were analyzed by nano-electrospray ionization MS/MS (ESI-Q-TOF) with a Q-TOF-Global (Micromass-Waters). Samples were resuspended in 12 $\mu \mathrm{L}$ of a $10 \%$ formic acid solution, and $4 \mu \mathrm{L}$ were injected for chromatographic separation onto a reverse-phase capillary $\mathrm{C}_{18}$ column (75 $\mu \mathrm{m}$ of internal diameter and 15 $\mathrm{cm}$ of length, PepMap column, LC Packings). The eluted peptides were ionized via coated nano-ES needles (Pico$\mathrm{Tip}^{\mathrm{TM}}$, New Objective). A capillary voltage of 1,800-2,200
$\mathrm{V}$ was applied together with a cone voltage of $80 \mathrm{~V}$. The collision in the CID (collision-induced dissociation) was 20-35 eV with argon as collision gas. Data were generated in a PKL file format, which were submitted for database searching in the MASCOT server.

\section{Western blot validation}

$20 \mu \mathrm{g}$ of total protein preparation were subjected to SDS-PAGE (12\% polyacrylamide gel) and electrotransferred onto a polyvinylidene difluoride membrane (Hybond-P, Amersham Bioscience). After blotting, the membrane was washed with TBS containing $0.05 \%$ Tween-20 (T-TBS) (v/v). The SNAPi.d. protein detection System (Millipore) was employed for the immunodetection. The membrane was blocked with $1 \%(\mathrm{w} / \mathrm{v})$ serum albumin in T-PBS for $10 \mathrm{~min}$ and incubated with primary antibodies [mouse anti-GRP94 monoclonal antibody (3/1,000, Abcam), mouse anti-pIgR monoclonal antibody (3/1,000, Santa Cruz Biotechnology) and rabbit polyclonal anti-IgGFcBP (1/500, Sigma-Aldrich)] for 10 min at room temperature. After a wash with T-TBS, the blot was incubated with $1 / 500$ diluted secondary antibody, an alkalin-phosphatase-conjugated antibody against mouse or rabbit IgG (Dako Cytomation), for 10 min at room temperature. Finally, the blot was washed with T-TBS and the colour was developed using BCIP/ NBT Liquid Substrate System (Sigma-Aldrich).

\section{Immunohistochemistry}

Tissue sections $(2-3 \mu \mathrm{m})$ were deparaffinized in xylene, rehydrated in a graded ethanol series and incubated in citrate buffer for $10 \mathrm{~min}$ in a microwave. Endogenous peroxidase activity was blocked with $0.5 \%(\mathrm{v} / \mathrm{v})$ hydrogen peroxide in methanol. After a rinse in PBS, bovine serum was applied to block non-specific interactions. Sections were then incubated $1 \mathrm{~h}$ with the primary antibody (rabbit polyclonal anti-IgGFcBP, 1/50, SigmaAldrich) at room temperature. After a rinse in PBS, sections were incubated $10 \mathrm{~min}$ with the primary antibody enhancer, and $1 \mathrm{~h}$ at room temperature with the secondary antibody bound to peroxidase. The peroxidase reaction was visualized by incubating with $\mathrm{DAB}(3,3$ 'diaminobenzidine). Finally, after a wash in water, the sections were counterstained with haematoxylin, dehydrated in a graded ethanol series, washed in xylene and mounted on a glass slide. Negative controls were performed using PBS instead of the primary antibody. The semiquantitative staining analysis was performed by expert pathologists.

\section{Statistical analyses}

Statistical analyses were performed using SPSS v. 15.00 for WINDOWS XP. The results were considered significant when $p \leq 0.05$. 


\section{Results}

Enrichment of $\alpha(1,6)$ fucosylated proteins from colorectal tissues by LCA-affinity chromatography

The success of a comparative glycoproteomic approach resides in the quality of the enrichment process. Therefore, lectin affinity chromatography protocols are commonly used to isolate different types of glycoproteins. In the present study, the lectin LCA, which recognizes $\alpha$ mannopyranosyl and $\alpha$-glucopyranosyl terminal residues of $\alpha(1,6)$ fucosylated proteins [18], was employed to separate this group of proteins. After chromatography, we obtained three distinct fractions: FI (which contains non-retained proteins), FII (composed of unspecific retained proteins and FIII, mainly enriched in $\alpha(1,6)$ fucosylated proteins). Five paired samples of healthy mucosa and tumour tissue were submitted to this prefractionation procedure, being the chromatography profile (Figure 1A and 1B) and the protein recovery very similar from both tissues (Table 1).

Proteins from the crude extract (TF) and the chromatography fractions were analyzed by means of 1D-SDSPAGE and lectin blot. The majority of the proteins

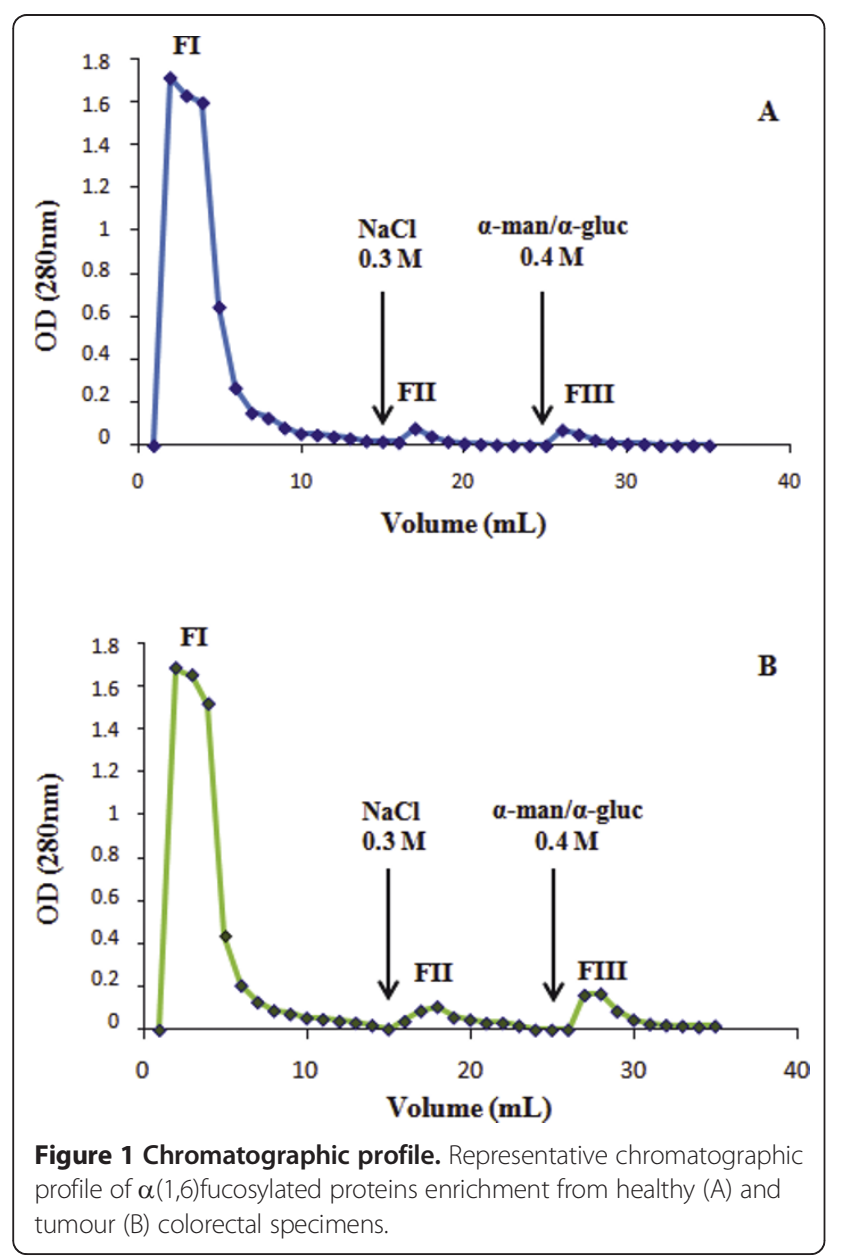

Table 1 Protein recovery during LCA-affinity chromatography

\begin{tabular}{cccccc}
\hline & & TF & FI & FII & FIII \\
\hline Healthy & Mean (mg) \pm & $4.83 \pm$ & $2.54 \pm$ & $0.21 \pm$ & $0.33 \pm$ \\
& SEM & 0.67 & 0.22 & 0.07 & 0.04 \\
$\boldsymbol{n}=\mathbf{5}$ & Percentage (\%) & 100 & 52.62 & 4.27 & 6.81 \\
\hline \multirow{2}{*}{ Tumour } & Mean (mg) \pm & $5.38 \pm$ & $3.03 \pm$ & $0.28 \pm$ & $0.44 \pm$ \\
& SEM & 0.33 & 0.50 & 0.06 & 0.05 \\
$\boldsymbol{n}=\mathbf{5}$ & Percentage (\%) & 100 & 56.24 & 5.19 & 8.23
\end{tabular}

SEM, standard error of the mean

observed in TF were eluted in FI (Figure 2, left). In both fractions we detected a strong band of about $60 \mathrm{kDa}$ corresponding to albumin. The elimination of the albumin-associated band (a non-glycosylated protein), allowed the visualization of minority proteins in FII and FIII (Figure 2A). Additionally, in the fraction enriched with $\alpha(1,6)$ fucosylated proteins, FIII, bands not visualized in the previous fractions were observed (Figure 2B), as well as others hardly expressed in FI and FII (Figure 2C). This electrophoretic profile ratified the appropriate functioning of the prefractionation procedure. Likewise, the lectin blot confirmed the enrichment of $\alpha(1,6)$ fucosylated proteins in FIII, since a higher number of LCA-reactive bands was observed in comparison to the other fractions (Figure 2, right).

Comparison of 1D-SDS-PAGE pattern of $\alpha(1,6)$ fucosylated proteins from healthy and tumour colorectal mucosa

With the aim to identify the $\alpha(1,6)$ fucosylated proteins differentially expressed in healthy and tumour colorectal mucosa, the band profile of the FIII fraction after the 1DSDS-PAGE was analyzed using the Quantity One Software (Bio-Rad). The analysis compared the intensity level of the detected and matched bands from paired tumour/healthy specimens from $5 \mathrm{CRC}$ patients. A total of 20 bands were compared between healthy and tumour mucosa. Although no statistically significant differences were found, some bands showed a clear trend of increase or decrease in tumour samples. In this sense, our interest was focused in two bands, $\mathrm{n}^{\circ} 5$ and $\mathrm{n}^{\circ} 8$ (Figure $2 \mathrm{~A}$ ). The first one showed a higher intensity in tumour compared to healthy mucosa $(+4.57$ fold-change) in 4 of 5 patients, while the second one showed a lower tumour intensity in 3 of 4 patients (-18.80 fold-change). The two bands were excised and submitted to mass spectrometry (MS) analysis.

\section{Identification of $\alpha(1,6)$ fucosylated proteins by mass spectrometry}

The CapLC-n-ESI-Q-TOF method allowed us the identification of proteins present in the $n^{\circ} 5$ and $n^{\circ} 8$ bands. The identity of these proteins and other characteristics, such as the experimental relative molecular mass $(\mathrm{Mr})$, the score and the SwissProt/NCBInr accession number, 


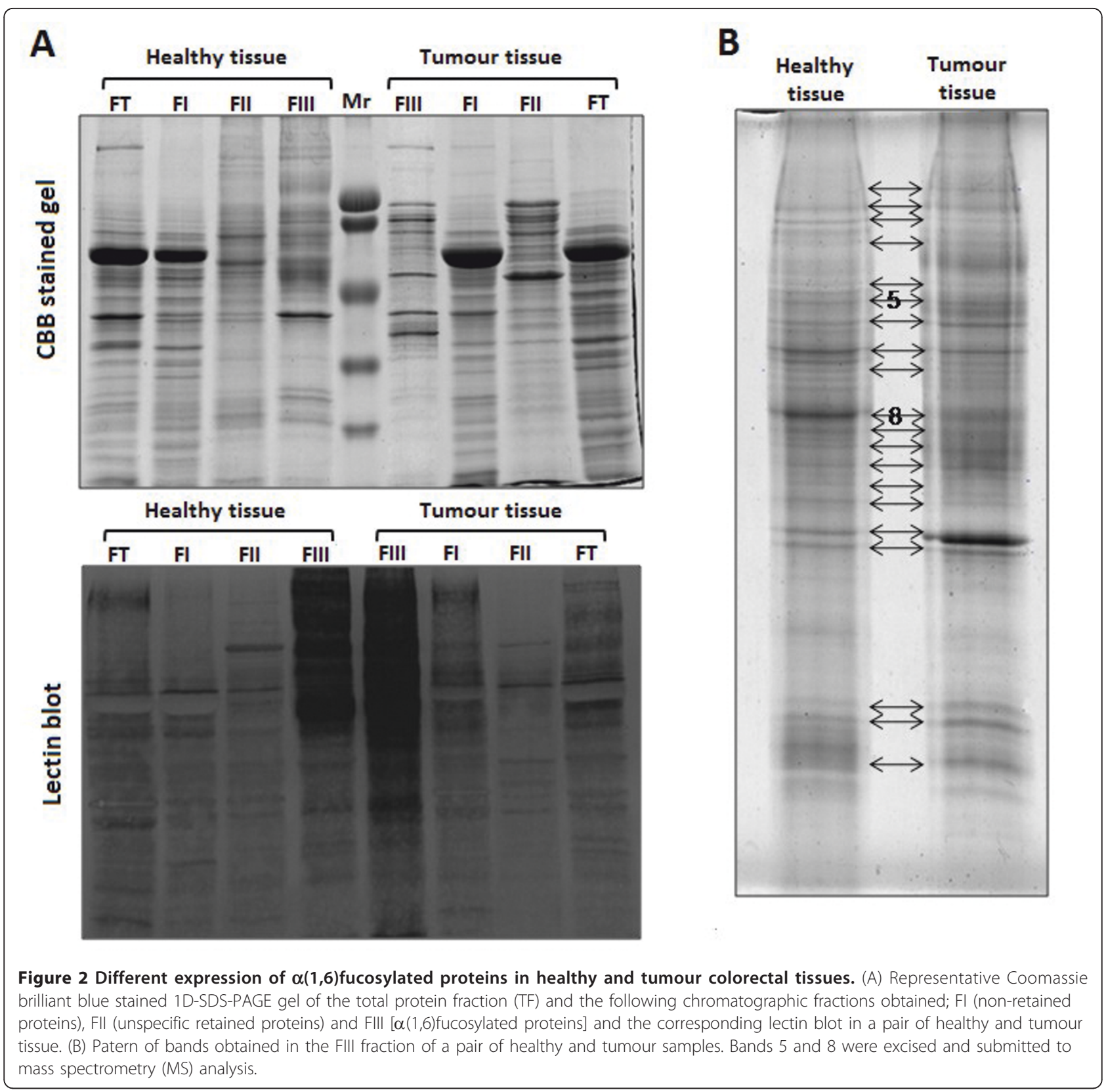

are summarized in Table 2. For the band $\mathrm{n}^{\circ} 5$, we found 5 candidate proteins with a score value higher than 37 (the limit to consider the identification of the protein not accidental). The protein with the highest score was the glucose regulated glycoprotein of $94 \mathrm{kDa}$ (GRP94), an endoplasmic reticulum chaperone which participates in the maintenance of the cell homeostasis, specially under stress conditions. The second candidate was the polymeric Ig receptor (pIgR), responsible for the transport of polymeric immunoglobulins (IgA and $\operatorname{IgG}$ ) across the mucose epithelial cells. The others candidates were the adhesion vascular protein 1 (VAP-1), the
fibulin-1C and the platelet glycoprotein IIIa (GP IIIa), implicated in cell adhesion, recognition process and the immune response, respectively.

On the other hand, the highest scored candidate protein integrating the band $\mathrm{n}^{\circ} 8$ was the IgG Fc binding protein $(\operatorname{IgGFcBP})$, a secreted protein present in the colon mucus. The other two proteins identified as potential candidates were the heavy chain of IgGB12 and the Fc region of IgA-1, both implicated in the modulation of the cell immune mechanisms.

All of these candidate proteins are glycosylated and some of them, such as PIgR, IgGFcBP, VAP-1 and the 
Table 2 Identification of $\alpha(1,6)$ fucosylated proteins by mass spectrometry

\begin{tabular}{|c|c|c|c|c|c|c|}
\hline Protein & $\begin{array}{c}\text { Band } \\
n^{\circ}\end{array}$ & $\begin{array}{c}\mathrm{Mr} \\
(\mathrm{kDa})\end{array}$ & $\begin{array}{l}\text { NCBInr Swiss-Prot } \\
\text { accession } n^{\circ}\end{array}$ & Function & Score & $\begin{array}{c}\text { Coverage } \\
\text { rate }(\%)\end{array}$ \\
\hline $\begin{array}{l}\text { Glucose regulated glycoprotein } \\
\text { of } 94 \mathrm{kDa}\end{array}$ & 5 & 92.7 & B4DHT9 & Stress response/chaperone & 743 & 20 \\
\hline $\begin{array}{l}\text { Polymeric immunoglobulins } \\
\text { receptor }\end{array}$ & 5 & 84.4 & P01833 & Immune response & 383 & 10 \\
\hline Vascular adhesión protein 1 & 5 & 85.1 & Q16853 & Cell adhesion molecule/Immune response & 361 & 11 \\
\hline Fibulin-1 C & 5 & 78.5 & P23142-4 & $\begin{array}{l}\text { Extracellular matrix component/cell } \\
\text { adhesion and migration }\end{array}$ & 339 & 12 \\
\hline Platelet glycoprotein IIIa & 5 & 87.4 & PO5106 & Cell adhesion molecule/Immune response & 156 & 5 \\
\hline IgG Fc binding protein & 8 & 59.6 & Q9Y6R7 & Cell adhesion molecule/lmmune response & 1320 & 6 \\
\hline Unknown protein product & 8 & 53.8 & Q6ZVX0 & unknown & 343 & 24 \\
\hline $\begin{array}{l}\text { Immunoglobulin G B12, heavy } \\
\text { chain }\end{array}$ & 8 & 51.2 & gi|15825648 & Cell adhesion molecule/Immune response & 272 & 16 \\
\hline $\begin{array}{l}\text { Immunoglobulin } \alpha-1, \text { constant } \\
\text { region }\end{array}$ & 8 & 54.3 & P01876 & Cell adhesion molecule/Immune response & 248 & 14 \\
\hline
\end{tabular}

Each protein score represents the sum of the score of each ion protein analyzed and this is, in turn considered numerically as $-10 *$ log $(p)$, where $p$ is the probability that the matching was made randomly and coverage rate (\%) represents the percentage of the total protein sequence that overlap with the peptide fragments.

GP-IIIA, have been previously described as $\alpha(1,6)$ fucosylated proteins, therefore validate the efficiency of the chromatography approach performed for the fractionation of specifically glycosylated proteins [18].

\section{Validation of GRP94, plgR and IgGFCBP alteration by Western blot}

In order to validate the results obtained by 1D-SDS-PAGE, three proteins, GRP94, pIgR and IgGFcBP were chosen to determine their expression in tumour and healthy neighboring tissue. This selection was performed taking into account their score and their possible implication in CRC development and/or progression. The total protein fraction (TF) of 20 paired samples was employed for Western blotting detection of GRP94 and IgGFcBP, while for pIgR we examined 12 patients. The analysis demonstrated higher levels of GRP94 expression in the tumour tissue in 15 patients of the total analyzed ( $p=0.01$, according to Wilcoxon's test, Figure 3). On the other hand, the pIgR was identified in the same band as GRP94, which showed a higher intensity in tumour tissue. However, after the specific immunodetection of $\mathrm{pIgR}$, no differences were observed between the tumour and healthy mucosa $(p=$ 0.87 , according to Wilcoxon's test, Figure 4). Finally, the Western blot for IgGFcBP allowed the visualization of two bands, corresponding to 108 and $52 \mathrm{kDa}$ (Figure 5). The expression of both isoforms decreased in the tumour tissue of 13 and 12 patients, respectively, being this decrease statistically significant for the $108 \mathrm{kDa}$ isoform $(p=0.005$ and $p=0.191$ according to Wilcoxon's test) (Figure 5). It is also important to highlight that IgGFcBP was identified in an electrophoretic band with lower levels of intensity in tumour tissue.

\section{Immuhistochemical analysis of IgGFcBP}

Since the IgGFcBP histology distribution in CRC has not been studied previously in order to assess how specific is the alteration of its expression during the carcinogenesis process 20 paired specimens of healthy and tumour mucosa as well as 6 polyps, were analyzed by immunohistochemistry. The presence of the protein was detected as a brown staining clearly localized in the intracellular mucus of goblet cells (Figure 6A). A positive IgGFcBP expression was observed in all the healthy specimens (Figure 6A), while in tumour only 3 cases (early stage CRC) were positive (Figure 6B). In these positive tumours, the IgGFcBP expression was confined to the non-infiltrating epithelia. In addition, although all tumour analyzed are no mucilaginous a higher mucinous component was observed in the 3 cases with positive IgGFcBP expression. The different IgGFcBP immunohistochemical expression in tumour $v s$. healthy tissue was statistically significant $(p=0.001$, according to Wilcoxon's test). Furthermore, 4 of the polyps analyzed expressed the IgGFcBP; one hyperplastic, two adenomatous, and one mixed of hyperplastic/adenomatous. Interestingly, the positive glands were placed in the non-dysplastic zones (Figure 6C).

\section{Discussion}

The scientific community shows an increasing interest in qualitative and quantitative alterations that different glycoproteins undergo during the malignant transformation process. This interest is fundamentally focused on the detection of new tumour biomarkers for diagnosis, prognosis and follow-up of the disease, as well as on the development of new therapeutic targets. Thus, a large 


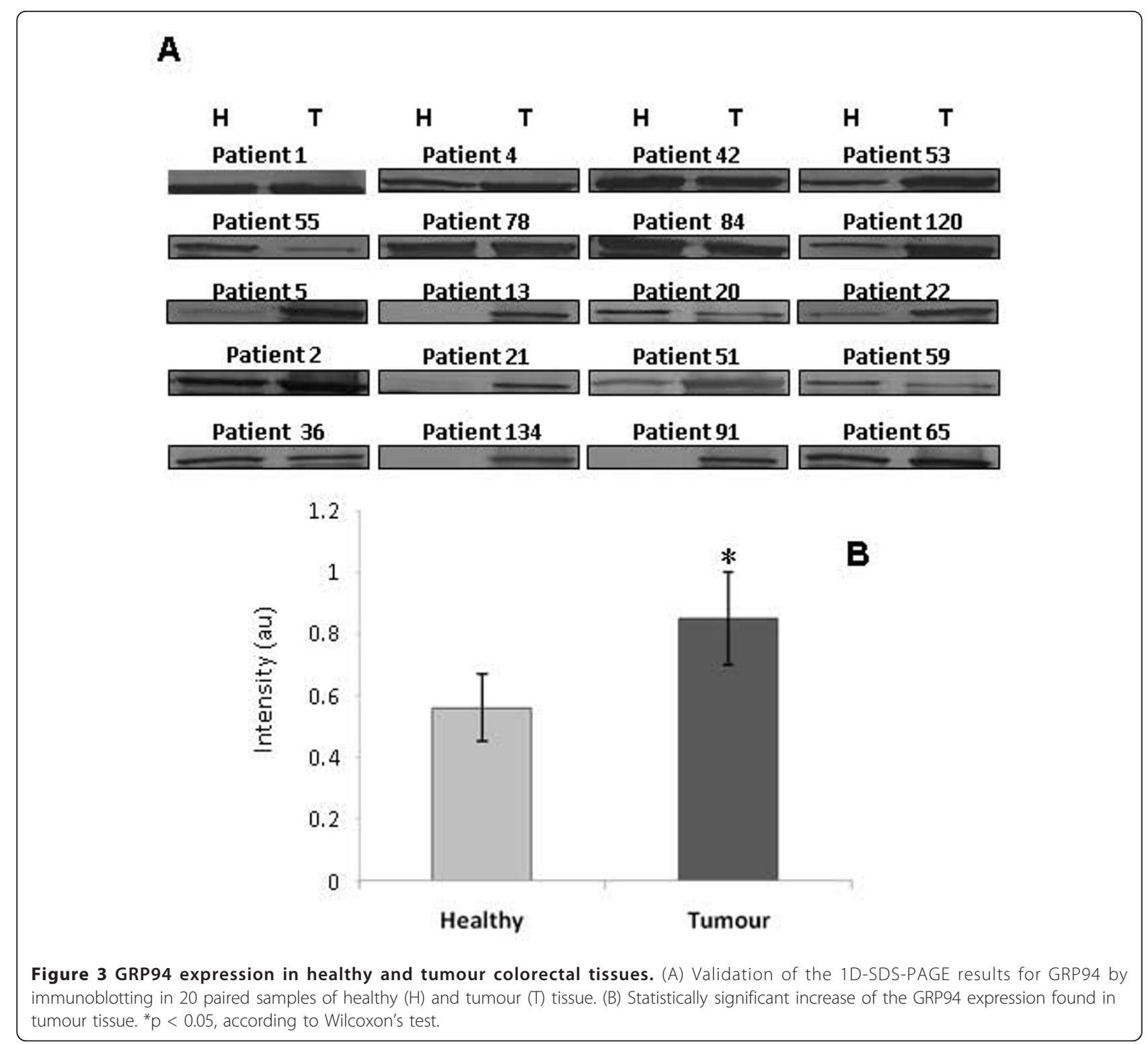

number of biomolecules currently used as tumour markers are glycoproteins $[24,25]$.

In particular, the study of the $\alpha(1,6)$ fucosylated proteins expressed in tumour cells has achieved high importance. Several researchers have reported the specific alteration of $\alpha(1,6) \mathrm{FT}$ activity and expression in malignant processes, such as HCC [26,27], thyroid papillary carcinoma [28] and ovarian adenocarcinoma [29]. Recently, we have also reported the alteration of the enzyme in CRC [22] and its implication in the disease progression (submitted data). In this sense, it is important to mention the critical role of $\alpha(1,6) \mathrm{FT}$ activity in the modulation of different growth factor receptors such as EGFR, TGF $\beta$ R or VEGFR. These molecules, strongly implicated in the carcinogenesis process and considered gold therapeutic targets for the treatment of solid tumours, need to be core-fucosylated to activate their intracellular signaling pathways [6-8]. Likewise, recent reports have shown that $\alpha(1,6)$ fucosylation of different adhesion molecules, such as adhesins or integrins, modify their functional activity, and could probably act as relevant factors for the acquisition of the migratory phenotype by the epithelial tumour cells $[6,10,11]$. Therefore, the identification and characterization of corefucosylated proteins differentially expressed in tumour cells is considered of great usefulness to discover new tumour biomarkers and therapeutic agents.

In the present study we combined a LCA-affinity chromatography with SDS-PAGE and mass spectrometry in order to identify $\alpha(1,6)$ fucosylated proteins 


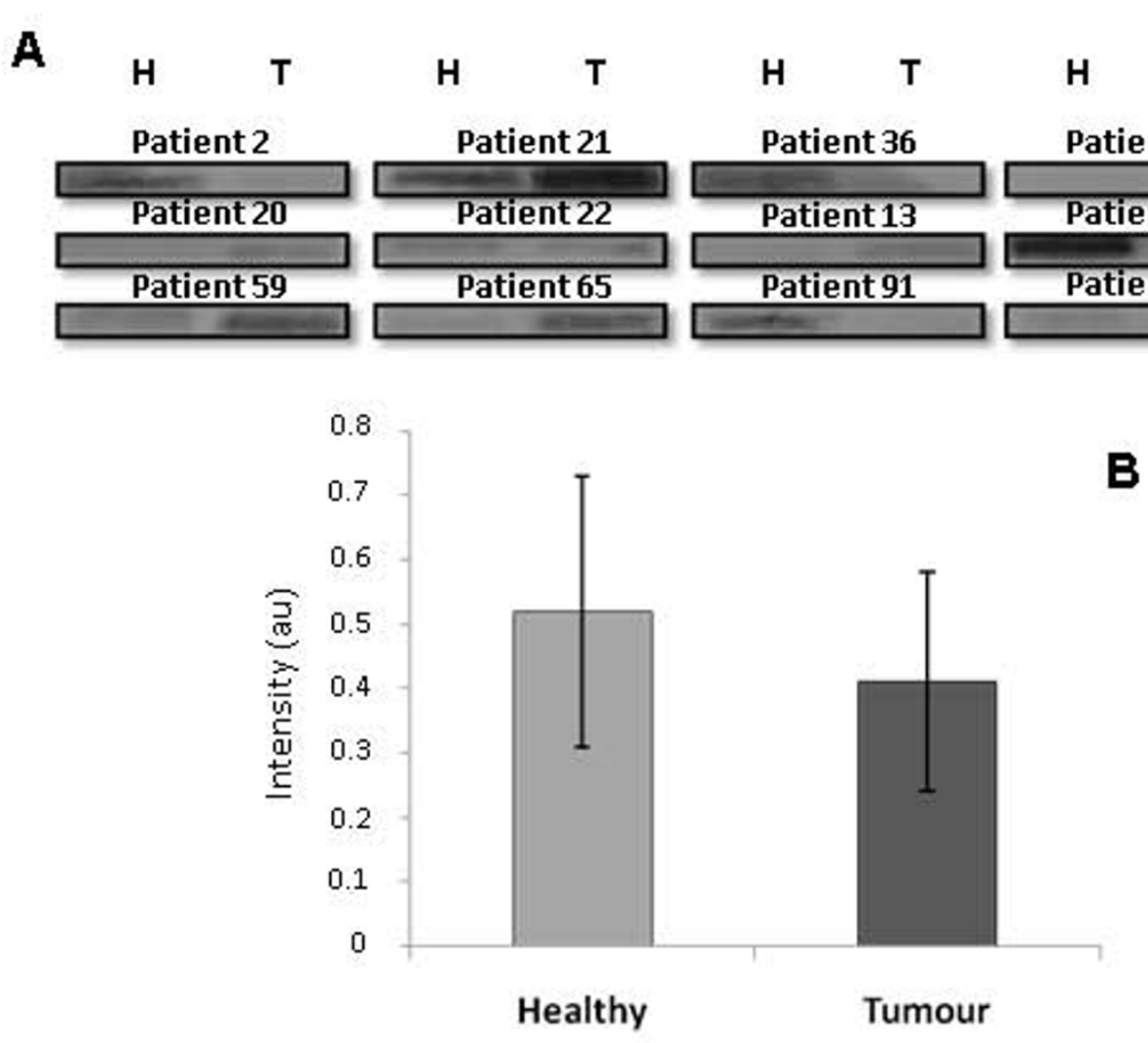

Figure 4 plgR expression in healthy and tumour colorectal tissues. (A) Validation of the 1D-SDS-PAGE results for plgR by immunoblotting in 12 paired samples of healthy $(\mathrm{H})$ and tumour $(\mathrm{T})$ tissue. (B) The statistical analysis showed no significant differences between healthy and tumour tissues according to Wilcoxon's test.

differentially expressed in the tumour tissue of 5 CRC patients. We identified a group of proteins candidates to be $\alpha(1,6)$ fucosylated and specifically regulated in colorectal tumours. Validating our approach, all the identified proteins have been described as glycoproteins, and most of them as $\alpha(1,6)$ fucosylated proteins. We selected three of them, the GRP94, the pIgR and the IgGFcBP in order to validate their altered expression during colorectal carcinogesis.

The GRP94 or endoplasmin is the most abundant glycoprotein in the endoplasmic reticulum. It belongs to the family of the heat-shock proteins, and together with GRP78 assists the folding and assembly of a wide range of proteins. The GRP94 also shows ATPase activity and plays an essential role in the cellular protection against different stress situations. Under pathological conditions, such as tumour growth, GRP94 is dramatically up-regulated as a survival mechanism [30], being its overexpression associated with a more aggressive tumour phenotype and a poor evolution of the disease [31,32]. In CRC, gene and protein GRP94 expression are strongly increased in both animal models and human tumours [33,34], and therefore GRP94 has been proposed as a useful diagnostic and prognostic marker for the disease. Concordantly, after an immunoblot analysis of the GRP94 expression in paired healthy and tumour colorectal specimens, we observed a significant increase in tumour tissue. In this sense, it is conceivable that up-regulation of GRP94 allows the correct folding of several oncogenic products promoting the colorectal carcinogenesis, although this increase has also been related with the acquisition of survival mechanisms by tumour cells to stand up lethal conditions, such as glucose starvation and hypoxia, and with the ability to form new distant solid tumours [30]. It also important to remark that although this protein is known to be glycosylated our study suggest for the first time its $\alpha(1,6)$ fucosylated status, however further studies should be developed to demonstrate this it.

In the same band where GRP94 was detected, MS analysis also identified the potential presence of pIgR. This glycosylated receptor is located in the basolateral membrane of the oral and gastrointestinal epithelial cells. Its main function is the transport of IgA and IgM polymeric forms across the epithelial cell membranes [35]. Recently, the $\alpha(1,6)$ fucosylation of this protein has 


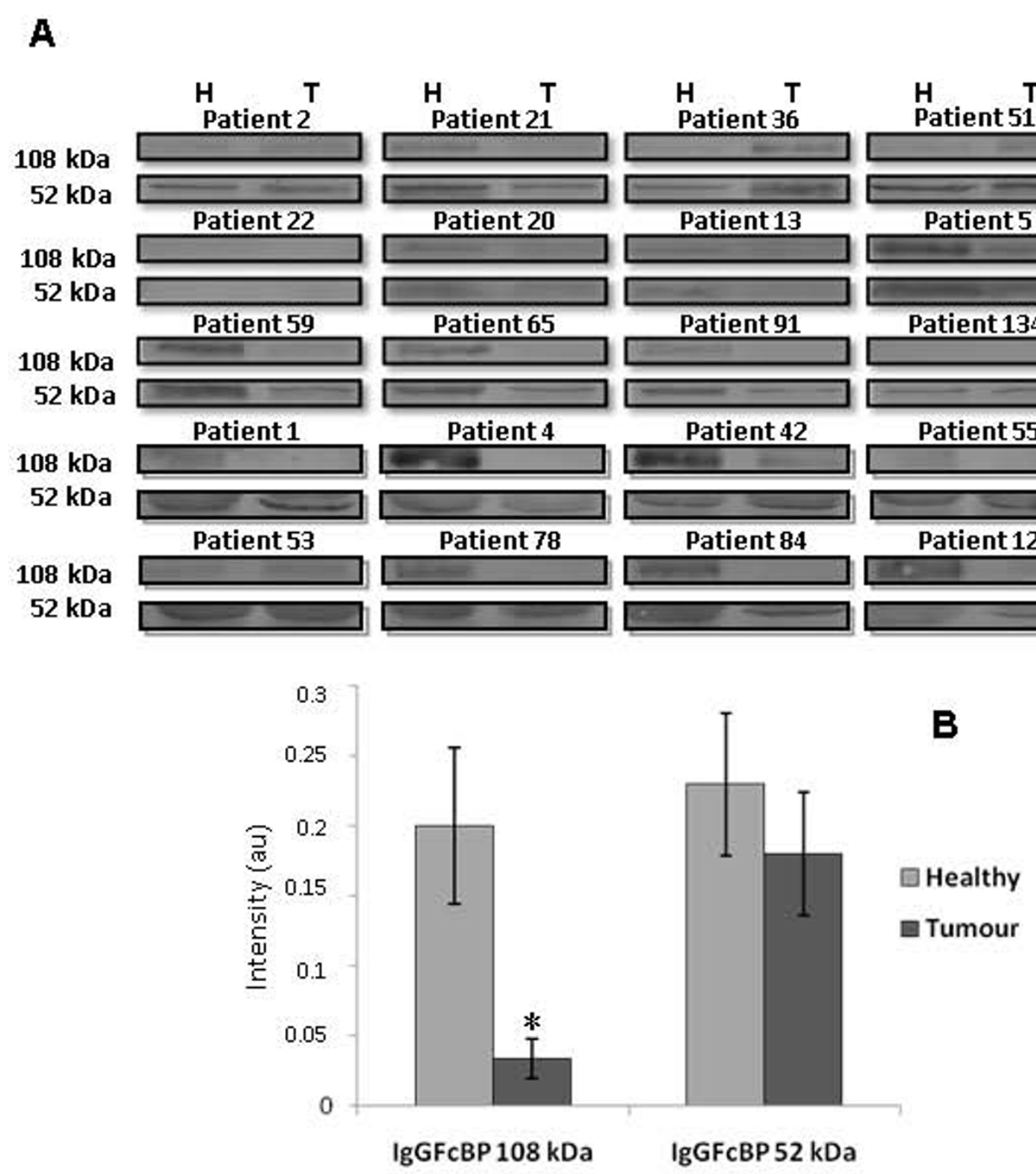

Figure 5 IgGFCBP expression in healthy and tumour colorectal tissues. (A) Validation of the 1D-SDS-PAGE results for IgGFCBP by immunoblotting in 20-paired samples of healthy $(\mathrm{H})$ and tumour $(\mathrm{T})$ tissue. The Western blot allowed the visualization of two underexpressed isoforms of $\sim 108$ and $\sim 52 \mathrm{kDa}$. (B) For the $\sim 108 \mathrm{kDa}$ band, this decrease was statistically significant. ${ }^{*} \mathrm{p}<0.05$, according to Wilcoxon's test.

been demonstrated in both, healthy and tumour hepatic specimens [36], confirming the results obtained in our study for colonic tissue. Interestingly, the importance of pIgR is not restricted to immunology, since changes in its expression, either increase or decrease, have been described in different types of tumours [37]. However, after our comparative immunoblot analysis between paired specimens of healthy and tumour mucosa, no significant differences were found in spite of the previous studies indicating an early decrease of pIgR expression during colorectal carcinogenesis [38]. It seems that the absence of pIgR in the tumour cells could induce a depletion of the immune response that promotes their malignant potential; nevertheless, its role in cancer development remains unknown.

Finally, we analyzed by Western blot and immunohistochemistry the expression of IgGFcBP, a protein secreted by the mucosa epithelial cells and present in the body fluids [31]. It specifically recognizes the constant fraction of IgG, and plays a relevant role in the structural maintenance of the mucosa through the binding to the MUC2 mucin [39]. Despite the theoretical molecular mass of IgGFcBP is $\sim 500 \mathrm{kDa}$ [31], SDSPAGE reports $\mathrm{Mr} \sim 100-80 \mathrm{kDa}$ depending on the tissue 


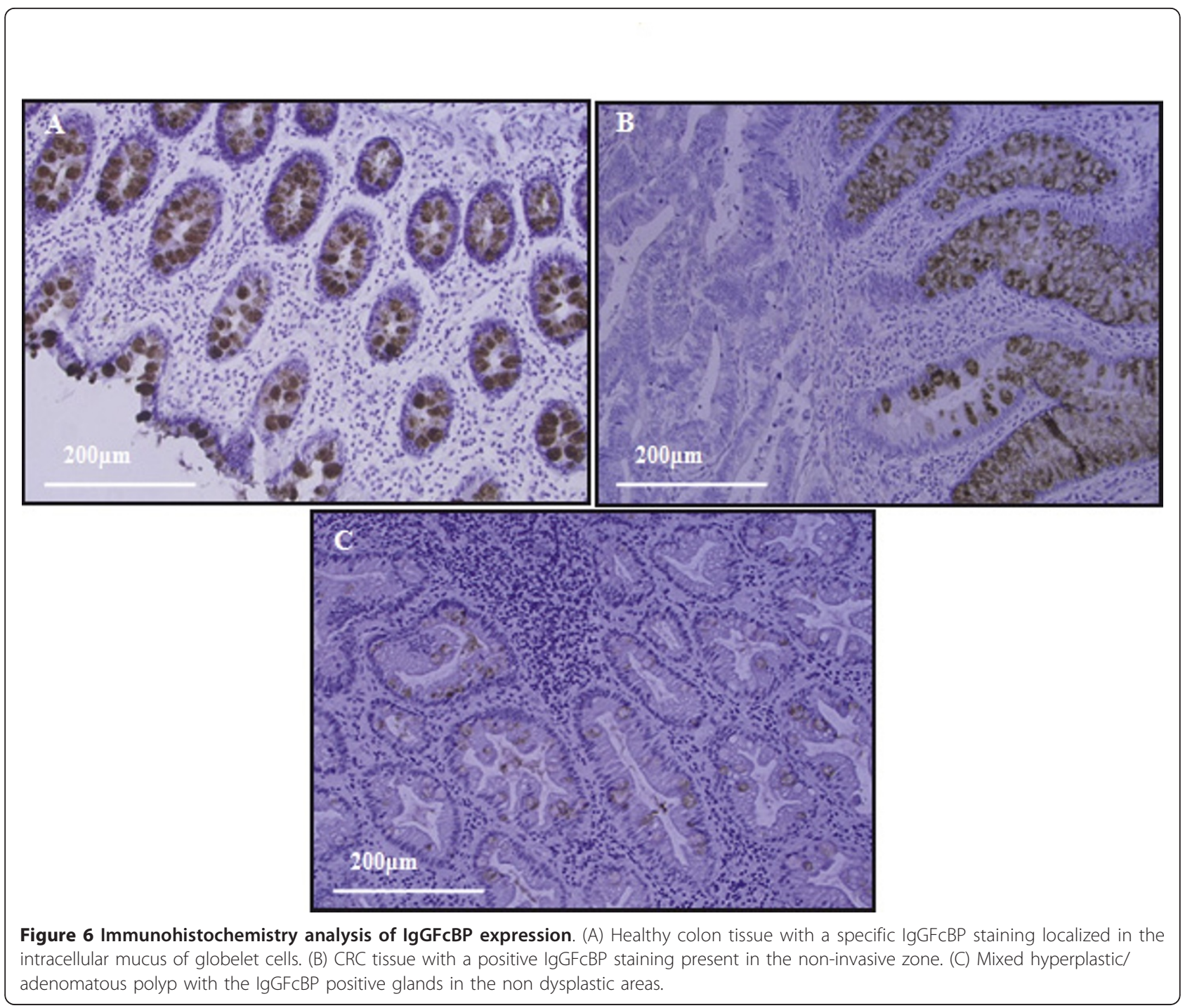

analyzed. In our study two bands of 108 and $52 \mathrm{kDa}$ were detected, suggesting a tissue specific proteolytic process. Interestingly, the two bands showed a clear decrease in tumour specimens, statistically significant for the $108 \mathrm{KDa}$ band. These results were confirmed by immunohistochemistry, since a positive IgGFcBP expression was observed in all the healthy specimens analyzed, while only 3 early staged tumours were found positive (with the expression mainly confined to the non-infiltrating epithelia). Concordantly with the specific expression of IgGFcBP in the goblet cells of the mucosa, the 3 positive tumours present higher percentage of mucinous component than the other specimens. It should be of great interest check the status of the IgGFcBP expression in mucilaginous tumours to demonstrate the independence between the tumour histology and the IgGFcBP downregulation. Furthermore, the analysis of 6 polyps showed expression of IgGFcBP in 4 of the specimens. Supporting our results, the lost of expression of this $\alpha(1,6)$ fucosylated protein in tumour specimens has also been reported in hepatic tissues [36] and the same tumour decrease of IgGFcBP has been described in animal models of CRC and human polyps $[40,41]$. The biological significance of the down-regulation of IgGFcBP in tumour cells is uncertain. In this sense, the binding between this protein and IgG could protect it from the action of bacterial proteases [31], promoting the immunological response of the mucosa. Thus, the IgGFcBP overexpression has been detected in ulcerous colitis and Cröhn patients [42]. Consequently, it is thought that low secreted levels of this protein in tumour cells could facilitate the immune evasion. However, the absence of IgGFcBP in the colon mucosa could also lead to the structural disorganization of intestinal mucus, promoting the exposure of mucosa to carcinogenic agents and, therefore, the appearance of premalignant lesions in 
the epithelium. Taking into account that increased levels of serum IgGFcBP have been observed in inflammatory processes, a possible decrease in CRC could be of great value as a biomarker for this neoplasia.

\section{Conclusion}

In conclusion, the present study confirmed the altered expression of GRP94 in CRC and demonstrated for the first time its core-fucosylated status. Besides, a strong down-regulation of the IgGFcBP associated to the dysplastic phenotype acquisition was determined in precancerous and cancerous lesions of colorectal mucosa. Despite the role of both molecules in CRC must be studied in depth, these results ratify the utility of screening $\alpha(1,6)$ fucosylated proteins differentially expressed in tumour colorectal mucosa as a way to identify molecules implicated in CRC carcinogenesis and progression. This same strategy improved with 2D-SDS-PAGE or HPLC, could serve as an important tool for the elucidation of novel biomarkers and/or therapeutic targets which may facilitate the clinical management of CRC patients.

\section{Acknowledgements \\ The members of the Pathology Service of the Complejo Hospitalario Universitario de Ourense (Ourense, Galicia, Spain) have played a very important role in the results of immunohistochemical evaluation and this kind collaboration is acknowledged. LMR and SVP are recipients of fellowships from the "Xunta de Galicia" (Spain). This project has been partially supported by the "Xunta de Galicia" Grant INCITE08PXIB310249PR.}

\section{Author details}

'Department of Biochemistry, Genetics and Immunology, Faculty of Biology, University of Vigo, Campus As Lagoas-Marcosende S/N, 36310, Vigo, Spain. ${ }^{2}$ Pathology Service, University Complex Hospital of Ourense, Ramón Puga 54, 32005, Ourense, Spain.

\section{Authors' contributions}

The work presented here was carried out in collaboration between all authors. LMR participated in the design of the study, the proteomic analysis, the results interpretation and the manuscript preparation. SVP carried out the immunohistochemical analysis and helped to draft the manuscript. EC collected the biological samples and carried out the valuation of the immunohistochemistry results. EGM and AFB carried out the design of the study, the results interpretation and the manuscript redaction. Finally, all authors have read and approved the final manuscript.

\section{Competing interests}

The authors declare that they have no competing interests.

Received: 2 June 2011 Accepted: 7 December 2011 Published: 7 December 2011

\section{References}

1. Landis SH, Murray T, Bolden S, Wingo PA: Cancer statistics, 1998. CA Cancer J Clin 1998, 48(1):6-29.

2. Varki A: Biological roles of oligosaccharides: all of the theories are correct. Glycobiology 1993, 3(2):97-130.

3. Hakomori S: Aberrant glycosylation in tumors and tumor-associated carbohydrate antigens. Adv Cancer Res 1989, 52:257-331.

4. Campion B, Leger D, Wieruszeski JM, Montreuil J, Spik G: Presence of fucosylated triantennary, tetraantennary and pentaantennary glycans in transferrin synthesized by the human hepatocarcinoma cell line Hep G2. Eur J Biochem 1989, 184(2):405-413.
5. Uozumi N, Teshima T, Yamamoto T, Nishikawa A, Gao YE, Miyoshi E, Gao CX, Noda K, Islam KN, Ihara Y, et al: A fluorescent assay method for GDP-L-Fuc:N-acetyl-beta-D-glucosaminide alpha 1-6fucosyltransferase activity, involving high performance liquid chromatography. $J$ Biochem 1996, 120(2):385-392.

6. Wang X, Fukuda T, Li W, Gao CX, Kondo A, Matsumoto A, Miyoshi E, Taniguchi N, Gu J: Requirement of Fut8 for the expression of vascular endothelial growth factor receptor-2: a new mechanism for the emphysema-like changes observed in Fut8-deficient mice. J Biochem 2009, 145(5):643-651

7. Wang X, Gu J, Ihara H, Miyoshi E, Honke K, Taniguchi N: Core fucosylation regulates epidermal growth factor receptor-mediated intracellular signaling. J Biol Chem 2006, 281(5):2572-2577.

8. Wang X, Inoue S, Gu J, Miyoshi E, Noda K, Li W, Mizuno-Horikawa Y, Nakano M, Asahi M, Takahashi M, et al: Dysregulation of TGF-beta1 receptor activation leads to abnormal lung development and emphysema-like phenotype in core fucose-deficient mice. Proc Natl Acad Sci USA 2005, 102(44):15791-15796.

9. Zhao Y, Itoh S, Wang X, Isaji T, Miyoshi E, Kariya Y, Miyazaki K, Kawasaki N, Taniguchi N, Gu J: Deletion of core fucosylation on alpha3beta1 integrin down-regulates its functions. J Biol Chem 2006, 281(50):38343-38350.

10. Geng F, Shi BZ, Yuan YF, Wu XZ: The expression of core fucosylated Ecadherin in cancer cells and lung cancer patients: prognostic implications. Cell Res 2004, 14(5):423-433.

11. Osumi D, Takahashi M, Miyoshi E, Yokoe S, Lee SH, Noda K, Nakamori S, Gu J, Ikeda Y, Kuroki Y, et al: Core fucosylation of E-cadherin enhances cell-cell adhesion in human colon carcinoma WiDr cells. Cancer Sci 2009, 100(5):888-895.

12. Yamashiki N, Seki T, Wakabayashi M, Nakagawa T, Imamura M, Tamai T, Nishimura A, Inoue K, Okamura A, Arita S, et al: Usefulness of Lens culinaris agglutinin A-reactive fraction of alpha-fetoprotein (AFP-L3) as a marker of distant metastasis from hepatocellular carcinoma. Oncol Rep 1999, 6(6):1229-1232

13. Comunale MA, Lowman M, Long RE, Krakover J, Philip R, Seeholzer S, Evans AA, Hann HW, Block TM, Mehta AS: Proteomic analysis of serum associated fucosylated glycoproteins in the development of primary hepatocellular carcinoma. J Proteome Res 2006, 5(2):308-315.

14. Ang IL, Poon TC, Lai PB, Chan AT, Ngai SM, Hui AY, Johnson PJ, Sung JJ: Study of serum haptoglobin and its glycoforms in the diagnosis of hepatocellular carcinoma: a glycoproteomic approach. J Proteome Res 2006, 5(10):2691-2700.

15. Barrabes S, Pages-Pons L, Radcliffe CM, Tabares G, Fort E, Royle L, Harvey DJ, Moenner M, Dwek RA, Rudd PM, et al: Glycosylation of serum ribonuclease 1 indicates a major endothelial origin and reveals an increase in core fucosylation in pancreatic cancer. Glycobiology 2007, 17(4):388-400.

16. Okuyama N, Ide $Y$, Nakano M, Nakagawa T, Yamanaka K, Moriwaki K, Murata K, Ohigashi H, Yokoyama S, Eguchi H, et al: Fucosylated haptoglobin is a novel marker for pancreatic cancer: a detailed analysis of the oligosaccharide structure and a possible mechanism for fucosylation. Int J Cancer 2006, 118(11):2803-2808.

17. Mechref $Y$, Madera M, Novotny MV: Glycoprotein enrichment through lectin affinity techniques. Methods Mol Biol 2008, 424:373-396.

18. Toyoshima S, Osawa T, Tonomura A: Some properties of purified phytohemagglutinin from Lens culinaris seeds. Biochim Biophys Acta 1970, 221(3):514-521.

19. Kochibe N, Furukawa K: Purification and properties of a novel fucosespecific hemagglutinin of Aleuria aurantia. Biochemistry 1980, 19(13):2841-2846.

20. Comunale MA, Wang M, Hafner J, Krakover J, Rodemich L, Kopenhaver B, Long RE, Junaidi O, Bisceglie AM, Block TM, et al: Identification and development of fucosylated glycoproteins as biomarkers of primary hepatocellular carcinoma. J Proteome Res 2009, 8(2):595-602.

21. Dai Z, Fan J, Liu Y, Zhou J, Bai D, Tan C, Guo K, Zhang Y, Zhao Y, Yang P: Identification and analysis of alpha1,6-fucosylated proteins in human normal liver tissues by a target glycoproteomic approach. Electrophoresis 2007, 28(23):4382-4391.

22. Muinelo-Romay L, Vazquez-Martin C, Villar-Portela S, Cuevas E, Gil-Martin E, Fernandez-Briera A: Expression and enzyme activity of alpha $(1,6)$ fucosyltransferase in human colorectal cancer. Int J Cancer 2008, 123(3):641-646. 
23. Muinelo-Romay L, Cuevas E, Gil-Martín E, Fernández-Briera A: $a(1,6)$ Fucosyltransferase Expression Is an Independent Prognostic Factor for Disease-Free Survival in Colorectal Carcinoma. Human Pathology 2011.

24. Hammarstrom S: The carcinoembryonic antigen (CEA) family: structures, suggested functions and expression in normal and malignant tissues. Semin Cancer Biol 1999, 9(2):67-81.

25. Tomlinson IP, Whyman A, Barrett JA, Kremer JK: Tumour marker CA15-3: possible uses in the routine management of breast cancer. Eur $J$ Cancer 1995, 31A(6):899-902.

26. Hutchinson WL, Du MQ, Johnson PJ, Williams R: Fucosyltransferases: differential plasma and tissue alterations in hepatocellular carcinoma and cirrhosis. Hepatology 1991, 13(4):683-688.

27. Miyoshi E, Noda K, Ko JH, Ekuni A, Kitada T, Uozumi N, Ikeda Y, Matsuura N, Sasaki Y, Hayashi N, et al: Overexpression of alpha1-6 fucosyltransferase in hepatoma cells suppresses intrahepatic metastasis after splenic injection in athymic mice. Cancer Res 1999, 59(9):2237-2243.

28. Ito Y, Miyauchi A, Yoshida H, Uruno T, Nakano K, Takamura Y, Miya A, Kobayashi K, Yokozawa T, Matsuzuka F, et al: Expression of alpha1,6fucosyltransferase (FUT8) in papillary carcinoma of the thyroid: its linkage to biological aggressiveness and anaplastic transformation. Cancer Lett 2003, 200(2):167-172.

29. Takahashi T, Ikeda Y, Miyoshi E, Yaginuma Y, Ishikawa M, Taniguchi N: alpha1, 6fucosyltransferase is highly and specifically expressed in human ovarian serous adenocarcinomas. Int J Cancer 2000, 88(6):914-919.

30. Li Z, Srivastava PK: Tumor rejection antigen gp96/grp94 is an ATPase: implications for protein folding and antigen presentation. EMBO J 1993, 12(8):3143-3151.

31. Harada N, lijima S, Kobayashi K, Yoshida T, Brown WR, Hibi T, Oshima A, Morikawa M: Human IgGFc binding protein (FcgammaBP) in colonic epithelial cells exhibits mucin-like structure. J Biol Chem 1997, 272(24):15232-15241.

32. Nomura H, Uzawa K, Yamano Y, Fushimi K, Ishigami T, Kato Y, Saito K, Nakashima D, Higo M, Kouzu Y, et al: Network-based analysis of calciumbinding protein genes identifies Grp94 as a target in human oral carcinogenesis. Br J Cancer 2007, 97(6):792-801.

33. Heike M, Frenzel C, Meier D, Galle PR: Expression of stress protein gp96, a tumor rejection antigen, in human colorectal cancer. Int J Cancer 2000, 86(4):489-493.

34. Wang X, Wang Q, Guo L, Ying X, Zhao Y: Immunolocalisation of heat shock protein 72 and glycoprotein 96 in colonic adenocarcinoma. Acta Histochem 2008, 110(2):117-123.

35. Kaetzel CS: The polymeric immunoglobulin receptor: bridging innate and adaptive immune responses at mucosal surfaces. Immunol Rev 2005, 206:83-99.

36. Jia W, Lu Z, Fu Y, Wang HP, Wang LH, Chi H, Yuan ZF, Zheng ZB, Song LN, $\mathrm{Han} \mathrm{HH}$, et al: A strategy for precise and large scale identification of core fucosylated glycoproteins. Mol Cell Proteomics 2009, 8(5):913-923.

37. Chang Y, Lee TC, Li JC, Lai TL, Chua HH, Chen CL, Doong SL, Chou CK, Sheen TS, Tsai CH: Differential expression of osteoblast-specific factor 2 and polymeric immunoglobulin receptor genes in nasopharyngeal carcinoma. Head Neck 2005, 27(10):873-882.

38. Traicoff JL, De Marchis L, Ginsburg BL, Zamora RE, Khattar NH, Blanch VJ, Plummer S, Bargo SA, Templeton DJ, Casey G, et al: Characterization of the human polymeric immunoglobulin receptor (PIGR) 3'UTR and differential expression of PIGR mRNA during colon tumorigenesis. J Biomed Sci 2003, 10(6 Pt 2):792-804.

39. Johansson ME, Thomsson KA, Hansson GC: Proteomic analyses of the two mucus layers of the colon barrier reveal that their main component, the Muc2 mucin, is strongly bound to the Fcgbp protein. J Proteome Res 2009, 8(7):3549-3557.

40. Lee S, Bang S, Song K, Lee I: Differential expression in normal-adenomacarcinoma sequence suggests complex molecular carcinogenesis in colon. Oncol Rep 2006, 16(4):747-754.

41. Yasui $Y$, Tanaka T: Protein expression analysis of inflammation-related colon carcinogenesis. J Carcinog 2009, 8:10

42. Kobayashi K, Yagasaki M, Harada N, Chichibu K, Hibi T, Yoshida T, Brown WR, Morikawa M: Detection of Fcgamma binding protein antigen in human sera and its relation with autoimmune diseases. Immunol Lett 2001, 79(3):229-235.

\section{Pre-publication history}

The pre-publication history for this paper can be accessed here: http://www.biomedcentral.com/1471-2407/11/508/prepub

doi:10.1186/1471-2407-11-508

Cite this article as: Muinelo-Romay et al.: Identification of $\alpha(1,6)$ fucosylated proteins differentially expressed in human colorectal cancer. BMC Cancer 2011 11:508.

\section{Submit your next manuscript to BioMed Central and take full advantage of:}

- Convenient online submission

- Thorough peer review

- No space constraints or color figure charges

- Immediate publication on acceptance

- Inclusion in PubMed, CAS, Scopus and Google Scholar

- Research which is freely available for redistribution

Submit your manuscript at www.biomedcentral.com/submit
C Biomed Central 